\title{
Research Activities of Spinal Fusion in Various Subspecialties by Different Surgeons: A Bibliometric Study
}

\author{
Chaobo FENG ${ }^{1,{ }^{*}}$, Jianfeng PING ${ }^{2,{ }^{*},}$, Jiajun DENG ${ }^{3,{ }^{*}}$, Guoxin FAN ${ }^{1,{ }^{*}}$, Shisheng HE ${ }^{1,{ }^{*}}$ \\ ${ }^{1}$ Tongji University School of Medicine, Shanghai Tenth People's Hospital, Orthopedic Department, Shanghai, China \\ ${ }^{2}$ Zhejiang University School of Medicine, Shaoxing People's Hospital, China \\ ${ }^{3}$ Tongji University School of Medicine, Shanghai Pulmonary Hospital, Department of Thoracic Surgery, Shanghai, China \\ These authors equally contribute to the work.
}

Corresponding author: Guoxin FAN, Shisheng HE gfan@tongji.edu.cn, tjhss7418@foxmail.com

\section{ABSTRACT}

AIM: To conduct a scientometric assessment of the research activities of spinal fusion in various subspecialties carried out by different surgeons.

MATERIAL and METHODS: All articles regarding spinal fusion research on Web of Science from the year 1994 to 2015 were identified and analyzed in the following aspects: year of publication, publication journal, number of times cited, Hirsch index ( $\mathrm{H}$-index), spine surgeon specialty, and country/territory.

RESULTS: A total of 15060 articles were identified, and the research productivity of spinal fusion has grown steadily over the last two decades. The average research productivity of spinal fusion each year was $109.09 \pm 23.26$ articles for cervical spine, $90.09 \pm 52.56$ articles for thoracic spine, and $304.91 \pm 181.63$ articles for lumbar. The research productivity of spinal fusion by neurosurgeons was 9474 articles published, while the orthopedic surgeons published 8263 articles. The average number of citations for spinal fusion articles was 19.61 times for neurosurgeons, and 20.36 times for orthopedic surgeons. In most countries neurosurgoens published more spinal fusion articles than orthopedic surgeons or at least the same amount, but orthopedic surgeons in China and Germany published far more spinal fusion articles $(>100)$ than neurosurgeons. The United States published the greatest number of articles (6819/15060, 45.28\%), followed by China (1280/15060, 8.50\%) and Germany (1252/15060, 8.31\%), and had the highest total citations (164378) and $\mathrm{H}$-index (144).

CONCLUSION: Neurosurgeons tend to publish more articles regarding spinal fusion, but orthopedic surgeons seem to have higher citations. North America, West Europe and East Asia were the most productive regions in spinal fusion research, and the United States made the most academic contributions to this area.

KEYWORDS: Spinal fusion, Scientometric evaluation, Orthopedic surgery, Neurosurgery, Bibliometric analysis

\section{INTRODUCTION}

$\mathrm{S}$ pinal fusion surgery is usually conducted in patients with trauma, degenerative spinal disease, neoplasms, or infections when available conservative treatments have failed (5). The primary goal of spinal fusion is to stabilize or restore spinal alignment, of which the efficacy and safety have been well validated over the past decades. In the United States, national survey data has suggested that the utilization of spinal fusion surgery is increasing more rapidly than that of nonfusion surgery (3). It was reported that cervical, thoracolumbar, and lumbar spinal fusion procedures have seen a rapid increase compared with other surgical
Chaobo FENG (D): 0000-0002-2737-573X Jianfeng PING (1): 0000-0002-9097-2772 Jiajun DENG (1) : 0000-0002-6834-0322
Guoxin FAN (1) : 0000-0002-6418-8343

Shisheng HE (1): 0000-0001-7796-1510 
procedures in clinical practice (2). Specifically, the utilization of lumbar fusions which has increased by $113 \%$ from 1996 to 2001 , compared with just a $13 \%$ to $15 \%$ increase for hip replacement and knee arthroplasty (3). The rapidly increased utilization of spinal fusion could be driven by many factors such as technology advancement, instrument development as well as the financial reimbursement for surgeons, hospitals, and the medical devices industry. The spinal implant and devices industry has an approximately $\$ 2$ billion market with a rapid growth rate of $18-20 \%$ every year (4). Another cause could be the rapid aging of our population in modern society due to degenerative spinal conditions. Spinal fusion is initially utilized in cases of severe scoliosis, spinal tuberculosis, and fractures. However, nowadays approximately $75 \%$ of spinal fusions are performed for spondylosis, disc disorders, and spinal stenosis exclusive of deformities (4). It was estimated that spinal fusion was performed in $50 \%$ of patients who had lumbar spinal stenosis and underwent spine surgery (3), although no absolute benefits of fusion in comparison to decompression alone for spinal stenosis have been shown in previous reports $(15,16)$. Until now, spinal fusion is a hot topic for medical research, with some issues still remaining under debate $(11,12,22)$. However, there is no scientometric evaluation providing a research background for future investigation and policy-making for funds concerning spinal fusion.

Medical informative science and public health research are essential for the improvement of evidence-based health funding policies and patient care (1). Due to the rapid development of internet technology, research information of medical science can be much more conveniently obtained than before. Thanks to powerful electronic search tools, informative bibliometric analyses are currently available to us (18). Bibliometrics, a mature method in information science, has been applied vastly in the medical field and its subspecialties $(8,9,19,24)$. To our knowledge, bibliometric studies analyzing time trends and geographic distributions of published articles concerning spine fusion have not been reported yet. We would find it very enlightening to gain insight into the research activities of different surgeons (i.e. neurosurgeons and orthopedic surgeons) in various subspecialties, such as cervical spine, thoracic spine and lumbar spine. Furthermore, we would also like to assess the quantity and citation times of the published articles in different journals. Therefore, the current study aims to conduct a scientometric evaluation of publication activities in the field of spinal fusion in different subspecialties done by neurosurgeons and orthopedic surgeons.

\section{MATERIAL and METHODS}

\section{Literature Searching}

A computerized literature search was conducted using the Science Citation Index Expanded (SCl-E) database of Web of Science (WoS) (Thomson Reuters, New York, USA) with the end date being December 2015, and the search strategy is specifically demonstrated in Figure 1. This platform was chosen because it is the world's leading database for collecting citations and information about academic impact, and has been widely used in similar studies $(10,25)$.

\section{Bibliometric Analysis}

The number of published articles was considered a quantitative index of research productivity. We depicted the time trends of all articles retrieved concerning spinal fusion and further analyzed the research productivity of neurosurgeons and orthopedic surgeons, and next we analyzed the research productivity in each of the subspecialties, namely cervical spine, thoracic spine, and lumbar spine. We also compared the productivity difference of different surgeons in the three subspecialties. Geographic variations of research productivity concerning spinal fusion were analyzed by ranking the number of published articles from different countries/areas. We also compared the average number of published articles adjusted by the population and Gross Domestic Product (GDP) in different countries/areas. The refinement tool on the website was used to identify the different data regarding surgical types, countries/areas and surgeons.

The number of citations was considered a vital indicator of published articles. We examined the total citations and mean citations for each country/area. Based on the categories of World Bank, we also calculated the proportion of articles that was attributed to high income, upper middle income, lower middle income, and low income countries. This categorization in terms of GDP per capita includes high income, $\$ 12746$ or more; upper middle income, $\$ 4126$ to $\$ 12745$; lower middle income, $\$ 1046$ to $\$ 4125$; and low income, $\$ 1045$ or less(8). Moreover, the research productivity of different countries was evaluated in relation to population size. The data for each

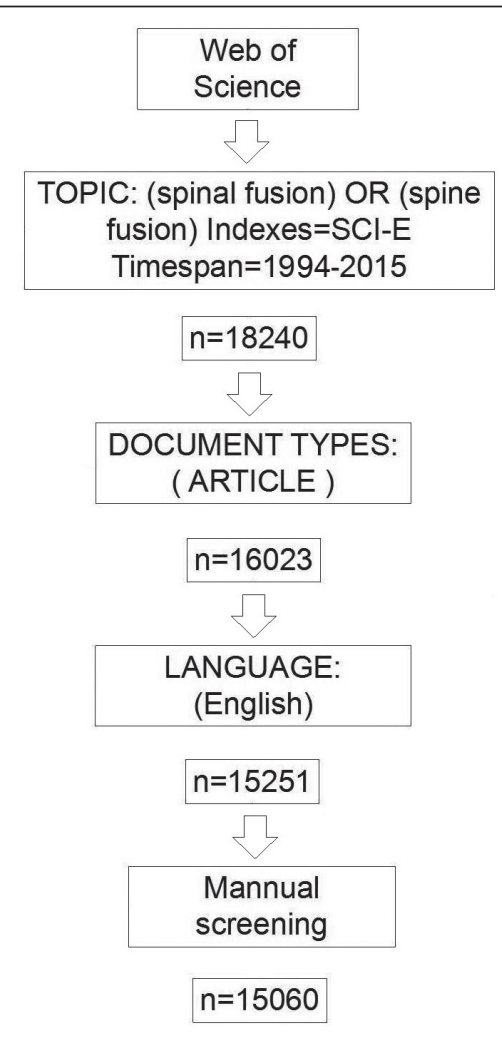

Figure 1: Data extraction and screening strategy. 
country was gathered from the Central Intelligence Agency and World Bank from the most recent reports. We examined the potential correlation between GDP of each country and its research productivity. To measure both the productivity and citation impact of the publications, we employed Hirsch index $(\mathrm{H}$-index) in our comprehensive analysis, which means $\mathrm{h}$ paper has been cited in other papers at least $\mathrm{h}$ times.

\section{Statistical Analysis}

All the statistical tests were performed using SPSS software version 19.0 (SPSS Inc., Chicago, IL, USA). Descriptive statistics (e.g., sum, average, SD) was used to depict the time trends and geographic distribution with the corresponding research quantity and citations. The statistical significance of potential correlation was determined by Pearson Correlation Test. A $p$ value of $<0.05$ was considered to be statistically significant.

\section{RESULTS}

A total of 15060 articles were identified from the online database WoS from 1994 to 2015 . The research productivity of spinal fusion in the last decade (2005-2015), which were 10821 articles, was 2.55 times higher than that of the first decade (1994-2004), 4239 articles (Figure 2A). The average research productivity of spinal fusion each year was 109.09 \pm 23.26 articles in cervical spine, $90.09 \pm 52.56$ articles in thoracic spine, and $304.91 \pm 181.63$ articles in lumbar spine

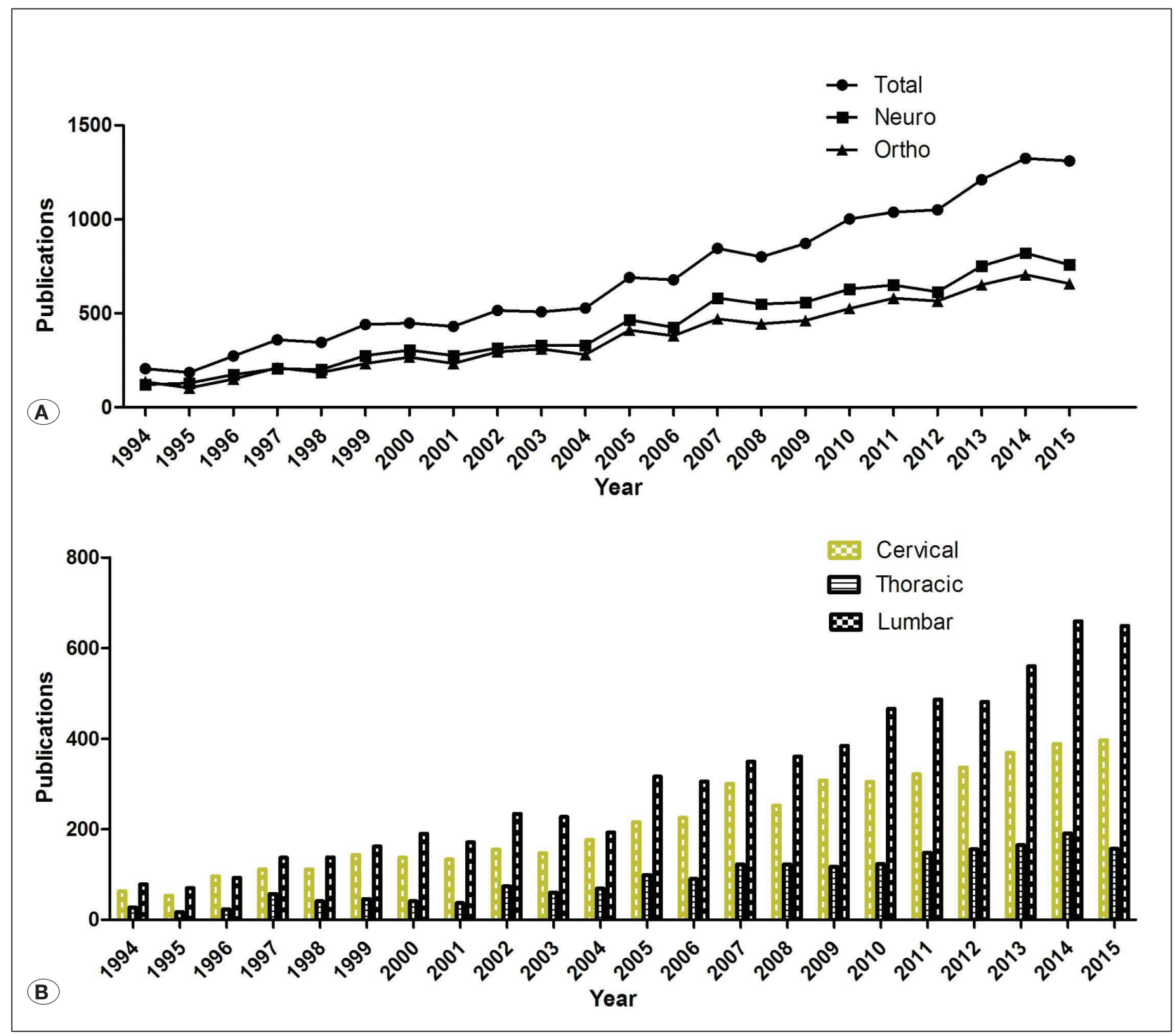

Figure 2: Time trends of research productivity concerning spinal fusion in different spine surgeons and different subspecialties. A) different spine surgeons; B) different subspecialties. 
(Figure 2B). The $\mathrm{H}$-index of spinal fusion articles was 124 in lumbar spine, 98 in cervical spine, and 74 in thoracic spine. The average number of citations of spinal fusion articles was 18.22 in lumbar spine, 14.72 in cervical spine, and 15.85 in thoracic spine. The average number of citations excluding self-citation of spinal fusion articles was 10.76 in lumbar spine, 8.74 in cervical spine, and 11.78 in thoracic spine.

With regards to the type of surgeon, research productivity of spinal fusion depicted that neurosurgeons published 9474 articles in the past two decades (1994-2015), while orthopedic surgeons published 8263 articles. The $\mathrm{H}$-index of spinal fusion articles was 138 for neurosurgeons, and 135 for orthopedic surgeons. The average number of citations of spinal fusion articles was 19.61 for neurosurgeons, and 20.36 for orthopedic surgeons. The average number of citations excluding selfcitation of spinal fusion articles was 12.97 for neurosurgeons, and 13.73 for orthopedic surgeons. Neurosurgeons published $155.45 \pm 78.33$ articles per year regarding cervical fusion, $63.05 \pm 37.77$ articles per year regarding thoracic fusion, and $206.59 \pm 118.59$ articles per year regarding lumbar fusion (Figure 3A). Orthopedic surgeons published $105.18 \pm 58.12$ articles per year regarding cervical fusion, $60.59 \pm 35.32$

Table I: Top 20 Productive Countries/Areas of Spinal Fusion Articles from Neurosurgeons or Orthopedic Surgeons

\begin{tabular}{|c|c|c|}
\hline Rank & Neurosurgeons & Orthopedic surgeons \\
\hline 1 & USA (4781) & USA (3919) \\
\hline 2 & JAPAN (865) & PEOPLES R CHINA (729) \\
\hline 3 & SOUTH KOREA (651) & GERMANY (708) \\
\hline 4 & PEOPLES R CHINA (605) & JAPAN (700) \\
\hline 5 & GERMANY (592) & SOUTH KOREA (390) \\
\hline 6 & ENGLAND (322) & FRANCE (303) \\
\hline 7 & CANADA (318) & ENGLAND (269) \\
\hline 8 & FRANCE (279) & CANADA (262) \\
\hline 9 & TURKEY (252) & SWITZERLAND (204) \\
\hline 10 & ITALY (238) & ITALY (185) \\
\hline 11 & SWITZERLAND (220) & TURKEY (159) \\
\hline 12 & TAIWAN (169) & TAIWAN (151) \\
\hline 13 & AUSTRALIA (159) & NETHERLANDS (130) \\
\hline 14 & INDIA (141) & SWEDEN (130) \\
\hline 15 & SPAIN (127) & AUSTRALIA (127) \\
\hline 16 & SWEDEN (122) & INDIA (111) \\
\hline 17 & NETHERLANDS (117) & AUSTRIA (110) \\
\hline 18 & AUSTRIA (103) & DENMARK (88) \\
\hline 19 & DENMARK (71) & GREECE (81) \\
\hline 20 & BRAZIL (58) & SPAIN (68) \\
\hline
\end{tabular}

articles per year regarding thoracic fusion, and $194.36 \pm$ 99.24 articles per year regarding lumbar fusion. Additionally, we summarized the top 20 productive countries/areas with the most spinal fusion articles written by neurosurgeons or orthopedic surgeons (Table I).

A total of 78 countries contributed to the research productivity of spinal fusion. The United States published the most number of articles (6819/15060, 45.28\%), followed by China (1280/15060, 8.50\%), Germany (1252/15060, 8.31\%), Japan (1210/15060, 8.04\%) and South Korea (857/15060, 5.69\%). A total of 17 productive countries (producing at least $1 \%$ of total articles) published almost all of the articles (including the four mentioned above) (Table II). Most of them were high-income countries. The nations that ranked $2^{\text {nd }}, 9^{\text {th }}$ and $14^{\text {th }}$ (China, Turkey and India respectively) were classified as middle income countries. Regarding production rate, Switzerland had the highest number of articles per capita (45.19), followed by the United States (21.22) and Sweden (19.59). When the number of articles was divided by the GDP of that country, South Korea ranked the at the top of the list (0.61), followed by Switzerland (0.52) and Turkey (0.47). Among the 17 countries, the United States had the highest number of citations (164378), followed by Germany (19331) and Japan (18328). Sweden had the highest mean number of citations (27.21), followed by the United States (24.11) and England (23.39). As for $\mathrm{H}$-index, the United States had the highest number at 144, followed by Germany (62), Japan (59) and England (55). There was a strong correlation between country GDP and research productivity of nations/areas $(R=0.917, p<0.001)$. However, there was no correlation between the population and research productivity of a nation/area $(R=0.133, p=0.612)$. Moreover, there was no correlation between GDP/capita and research productivity of nations/areas $(R=0.094, p=0.719)$.

As demonstrated in Figure 3A-D, Spine published the highest number of spine fusion articles (3205/15060, 21.28\%), followed by European Spine Journal (1208/15060, 8.02\%), Journal of Neurosurgery Spine (762/15060, 5.06\%), Journal of Spinal Disorders Techniques (672/15060, 4.46\%) and Spine Journal (520/ 15060, 3.45\%). Spine was also the most popular journal among neurosurgeons (Figure $3 \mathrm{C}$ ) and orthopedic surgeons (Figure 3D), followed by European Spine Journal, Journal of Neurosurgery Spine, Journal of Spinal Disorders Techniques, and Spine Journal. With regard to productivity distributions, we also summarized the top 5 journals in top 5 countries (Table III), and top 5 countries in top 5 journals (Table IV). Additionally, we also presented the top 4 productive countries in journals with high impact factors (IF>3), namely, Neurosurgery (IF: 3.78), J Neurosurg (IF: 3.44), J Bone Joint Surg Am (IF: 5.16), Clin Orthop Relat R (IF: 3.13) (Table V).

\section{DISCUSSION}

There has been a significant increase in the utilization of spinal fusion over the time. In this article, we assessed the quantity and citation number of spinal fusion articles in various subspecialties by different surgeons around the world. Some interesting findings are listed as follows: Neurosurgeons 
Feng C. et al: Research Activities in Spinal Fusion

Table II: Research Productivity and Citation Activities of Spinal Fusion in Different Countries

\begin{tabular}{lccccccrrr}
\hline Country & $\mathbf{n}$ & $\begin{array}{c}\text { n per million } \\
\text { population }\end{array}$ & Population & $\begin{array}{c}\text { GDP } \\
\text { (billion) }\end{array}$ & $\begin{array}{c}\text { GDP per } \\
\text { capita }\end{array}$ & N/GDP & $\begin{array}{c}\text { Total } \\
\text { citation }\end{array}$ & $\begin{array}{c}\text { Mean } \\
\text { citation }\end{array}$ & H-index \\
\hline United States & 6819 & 21.21860816 & 321368864 & 17420 & 54205.62 & 0.39 & 164378 & 24.11 & 144 \\
\hline China & 1280 & 0.936024627 & 1367485388 & 10350 & 7568.63 & 0.12 & 7993 & 6.24 & 33 \\
\hline Germany & 1252 & 15.48462268 & 80854408 & 3868 & 47839.07 & 0.32 & 19331 & 15.44 & 62 \\
\hline Japan & 1210 & 9.533590064 & 126919659 & 4601 & 36251.27 & 0.26 & 18328 & 15.15 & 59 \\
\hline South Korea & 857 & 17.44877492 & 49115196 & 1410 & 28708.01 & 0.61 & 8817 & 10.29 & 43 \\
\hline England & 562 & 8.769161984 & 64088222 & 2989 & 46638.83 & 0.19 & 13144 & 23.39 & 55 \\
\hline France & 527 & 7.918409906 & 66553766 & 2829 & 42506.98 & 0.19 & 9163 & 17.39 & 48 \\
\hline Canada & 525 & 14.95733484 & 35099836 & 1785 & 50854.93 & 0.29 & 10342 & 19.7 & 48 \\
\hline Turkey & 378 & 4.759849895 & 79414269 & 798.4 & 10053.60 & 0.47 & 3295 & 8.72 & 25 \\
\hline Switzerland & 367 & 45.1868606 & 8121830 & 701 & 86310.59 & 0.52 & 6493 & 17.69 & 42 \\
\hline Italy & 356 & 5.755384518 & 61855120 & 2141 & 34613.14 & 0.17 & 5257 & 14.77 & 36 \\
\hline Australia & 270 & 11.86760291 & 22751014 & 1455 & 63953.19 & 0.19 & 4351 & 16.11 & 37 \\
\hline Netherlands & 232 & 13.68900839 & 16947904 & 879.3 & 51882.52 & 0.26 & 5001 & 21.56 & 36 \\
\hline India & 218 & 0.174163753 & 1251695584 & 2049 & 1636.979 & 0.11 & 2344 & 10.75 & 23 \\
\hline Sweden & 192 & 19.58860661 & 9801616 & 571.1 & 58265.90 & 0.34 & 5225 & 27.21 & 38 \\
\hline Spain & 188 & 3.904778731 & 48146134 & 1381 & 28683.50 & 0.14 & 2078 & 11.05 & 24 \\
\hline Austria & 168 & 19.38711334 & 8665550 & 436.9 & 50418.03 & 0.38 & 2207 & 13.14 & 26 \\
\hline
\end{tabular}

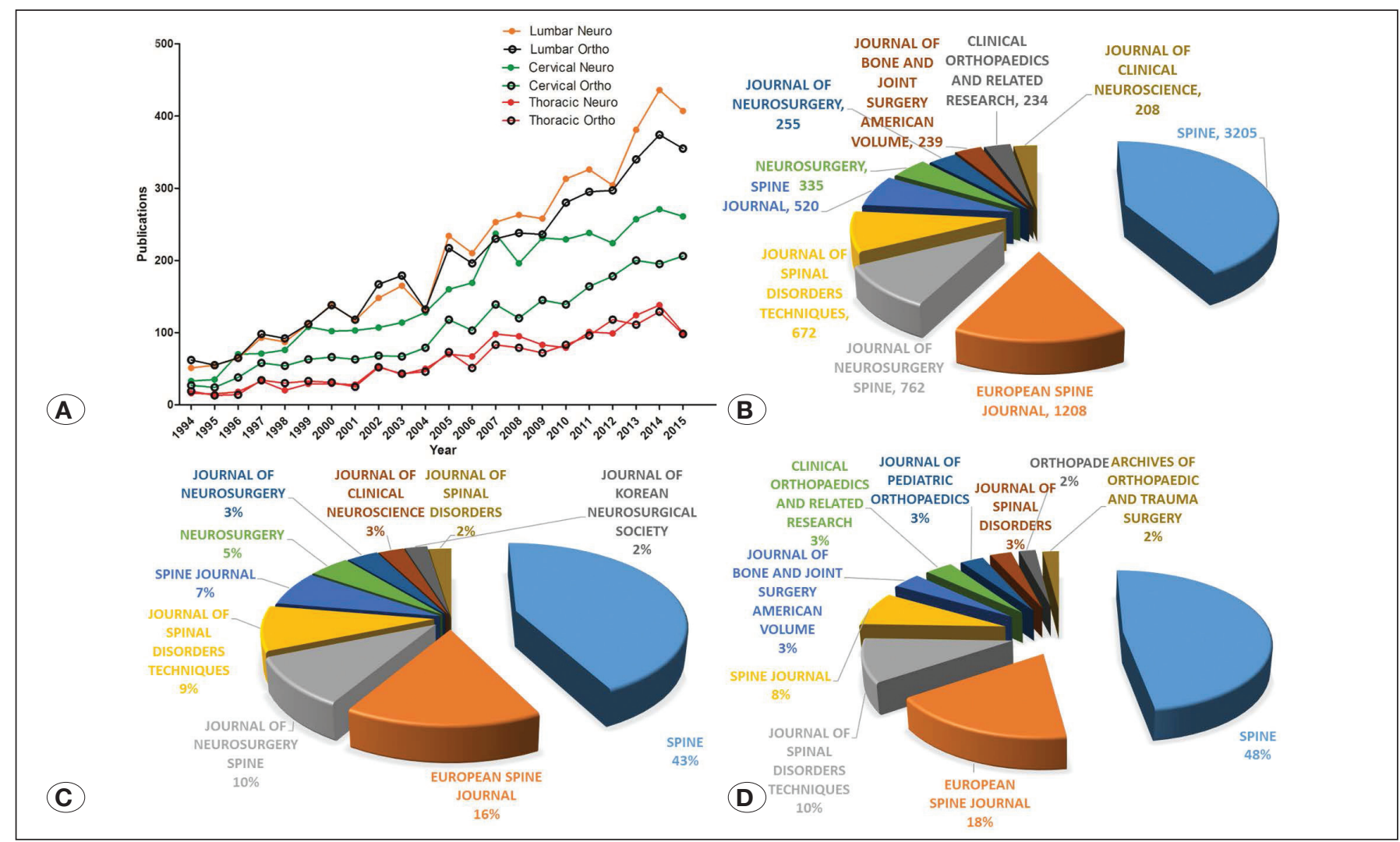

Figure 3: Research productions concerning spinal fusion from different spine surgeons in different subspecialties and spine journals.

A) Time trends in different subspecialties by different spine surgeons; B) journal ranking by total research productions; C) journal ranking by research productions from neurosurgeons; D) journal ranking by research productions from orthopedic surgeons. 
tended to publish more articles than orthopedic surgeons over time, but orthopedic surgeons seemed to have a higher number of citations. Lumbar fusion remained to be the most popular subspecialty for research activities. North America, West Europe and East Asia were the most productive regions, while the United States made the most academic contributions to this area having the highest $\mathrm{H}$-index. Some productive countries, like China, need to improve the citations of publications concerning spinal fusion. Finally, Spine was the most productive journal, followed by European Spine Journal, and then Journal of Neurosurgery Spine.
To the best of our knowledge, this is the first bibliometric analysis in the field of spinal fusion, which can provide a research background for future investigation and a thoughtprovoking reference for policy-making.

Many reports have witnessed a skyrocket increase in the utilization of spinal fusion in the past decades. Spinal fusion has risen from the 41st most common inpatient surgical procedure in 1997 to the 19th in 2003 in the United States (5). Specifically, over 122,000 lumbar fusions were performed in 2001, which represented a $220 \%$ increase from 1990 in fusions per 100,000 (6). Another report has demonstrated that

Table III: Top 5 Productive Journals in Top 5 Productive Countries

\begin{tabular}{ccccc}
\hline USA & CHINA & GERMANY & JAPAN & SOUTH KOREA \\
\hline $\begin{array}{c}\text { SPINE (2045/29.99\%) } \\
\text { J Neurosurg-Spine } \\
(471 / 6.91 \%)\end{array}$ & $\begin{array}{c}\text { EUR Spine J } \\
(165 / 12.89 \%)\end{array}$ & $\begin{array}{c}\text { EUR Spine J } \\
(162 / 12.94 \%)\end{array}$ & SPINE (156/12.46\%) $(309 / 25.54 \%)$ & $\begin{array}{c}\text { J Korean Neurosurg S } \\
(177 / 20.65 \%)\end{array}$ \\
\hline Spine J (337/4.94\%) & $\begin{array}{c}\text { J Spinal Disord Tech } \\
(73 / 5.70 \%)\end{array}$ & $\begin{array}{c}\text { ORTHOPADE } \\
(112 / 8.95 \%)\end{array}$ & $\begin{array}{c}\text { J Neurosurg-Spine } \\
(93 / 7.69 \%)\end{array}$ & EUR Spine J (57/6.65\%) \\
\hline $\begin{array}{c}\text { J Spinal Disord Tech } \\
(319 / 4.68 \%)\end{array}$ & $\begin{array}{c}\text { Arch Orthop Traum Su } \\
(55 / 4.30 \%)\end{array}$ & $\begin{array}{c}\text { Z Orthop Grenzgeb } \\
(59 / 4.71 \%)\end{array}$ & $\begin{array}{c}\text { J Spinal Disord Tech } \\
(82 / 6.78 \%)\end{array}$ & $\begin{array}{c}\text { J Spinal Disord Tech } \\
(56 / 6.53 \%)\end{array}$ \\
\hline $\begin{array}{c}\text { NEUROSURGERY } \\
(238 / 3.49 \%)\end{array}$ & $\begin{array}{c}\text { Chinese Med-J Peking } \\
(49 / 3.83 \%)\end{array}$ & $\begin{array}{c}\text { UNFALLCHIRURG } \\
(52 / 4.15 \%)\end{array}$ & $\begin{array}{c}\text { Neurol Med-Chir } \\
(44 / 3.64 \%)\end{array}$ & $\begin{array}{c}\text { J Neurosurg-Spine } \\
(54 / 6.30 \%)\end{array}$ \\
\hline
\end{tabular}

Table IV: Top 5 Productive Countries in Top 5 Productive Journals

\begin{tabular}{ccccc}
\hline $\begin{array}{c}\text { Spine } \\
(\mathbf{2 . 4 4 )}\end{array}$ & $\begin{array}{c}\text { EUR Spine J } \\
(\mathbf{2 . 1 3})\end{array}$ & $\begin{array}{c}\text { J Neurosurg-Spine } \\
\mathbf{( 2 . 1 3 )}\end{array}$ & $\begin{array}{c}\text { J Spinal Disord Tech } \\
(\mathbf{2 . 2 9})\end{array}$ & $\begin{array}{c}\text { Spine J } \\
\mathbf{( 2 . 6 6 )}\end{array}$ \\
\hline USA (2045/63.81\%) & USA (195/16.14\%) & USA (471/61.81\%) & USA (319/47.47\%) & USA (337/64.81\%) \\
\hline JAPAN (309/9.64\%) & CHINA (165/13.66\%) & JAPAN (93/12.21\%) & JAPAN (82/12.20\%) & $\begin{array}{c}\text { SOUTH KOREA } \\
(50 / 9.62 \%)\end{array}$ \\
\hline CHINA (174/5.43\%) & GERMANY (162/13.41\%) & $\begin{array}{c}\text { SOUTH KOREA } \\
(54 / 7.09 \%)\end{array}$ & CHINA (73/10.86\%) & CHINA (46/8.85\%) \\
\hline $\begin{array}{c}\text { SOUTH KOREA } \\
(160 / 4.99 \%)\end{array}$ & ITALY (106/8.78\%) & GERMANY (34/4.46\%) & $\begin{array}{c}\text { SOUTH KOREA } \\
(56 / 8.33 \%)\end{array}$ & JAPAN (24/4.62\%) \\
\hline GERMANY (156/4.87\%) & JAPAN (94/7.78\%) & CHINA (32/4.20\%) & CANADA (29/4.32\%) & CANADA (14/2.69\%) \\
\hline
\end{tabular}

Table V: Top 5 Productive Countries/Areas in Journals with High Impact Factors

\begin{tabular}{|c|c|c|c|}
\hline $\begin{array}{c}\text { Neurosurgery } \\
(3.78)\end{array}$ & $\begin{array}{c}\text { J Neurosurg } \\
\text { (3.44) }\end{array}$ & $\begin{array}{c}\text { J Bone Joint Surg Am } \\
(5.16)\end{array}$ & $\begin{array}{c}\text { Clin Orthop Relat R } \\
\text { (3.13) }\end{array}$ \\
\hline USA (238/71.05\%) & USA (162/63.53\%) & USA (203/84.94\%) & USA (150/64.10\%) \\
\hline GERMANY (21/6.27\%) & JAPAN (30/11.77\%) & JAPAN (11/4.60\%) & JAPAN (13/5.56\%) \\
\hline CANADA (17/5.08\%) & ENGLAND (20/7.84\%) & CANADA (6/2.51\%) & CANADA (12/5.13\%) \\
\hline SOUTH KOREA (13/3.88\%) & GERMANY (16/6.28\%) & SOUTH KOREA (5/2.09\%) & TAIWAN (8/3.42\%) \\
\hline ENGLAND (11/3.28\%) & CANADA (8/3.14\%) & ENGLAND (4/1.67\%) & GERMANY (7/2.99\%) \\
\hline
\end{tabular}


the number of spinal fusions rose from 174,223 procedures in 1998 to 413,171 in 2008 (23), while the most recent report has shown that spinal fusions totaled a whopping 465,000 procedures in 2011 and had the highest aggregate hospital costs ( $\$ 12.8$ billion) compared to any other surgical procedure in the United States (12). However, as demonstrated in our study, the increase of research productivity of spinal fusion has not caught up with the rapid increase of spinal fusion utilization in clinic over the past few decades. Worldwide geographic variations in use of spinal fusion indicated a poor level of consensus on the indications for the procedure (17). There is little evidence to support the benefits of spinal fusion for herniated disks and radiculopathy, although a growing proportion of cervical surgeries have involved a fusion procedure (2). Until now, we are still in need of more robust randomized controlled trials to confirm the indications of spinal fusion for degenerative conditions, especially for the newly added indication called discogenic pain, which is often diagnosed using provocative discography, which in itself is a controversial procedure (4).

In current practice, spinal fusion is mainly performed by neurosurgeons and orthopedic surgeons, both of whom seem to achieve equivalent outcomes on measured metrics of mortality, 30-day re-admission, and surgical site infection (20). Another study further confirmed spine surgeon specialty was not a risk factor for postoperative complication in singlelevel ACDFs (21). However, significant variation in decision to choose spinal fusion was observed for degenerative conditions of lumbar spine except lytic spondylolisthesis (13). Similar variation of surgical decision was observed for degenerative conditions of cervical spine except single-level disc herniation (14). Maybe the emphasis of research efforts should shift from how to perform fusion to identifying who should undergo fusion, regardless of the spine surgeon specialty. Our scientometric evaluation found that there were also some variations of research activities between neurosurgeons and orthopedic surgeons concerning spinal fusion. Considering their higher production of spinal fusion articles, neurosurgeons tend to be more active than orthopedic surgeons, either in cervical fusion, thoracic fusion or lumbar fusion. However, the citations of research productions from orthopedic surgeons seemed to be better with relatively higher number of average citations. In summary, research contributions regarding spinal fusion from neurosurgeons might be better than those from orthopedic surgeons because of the higher $\mathrm{H}$-index combining the quantity and citations assessment.

The debates over indications for spinal fusion have gained massive attention from national media and medical groups around the world (7). Theoretically, more research activities done for spinal fusion might help clarify the debates worldwide. As we have observed, the United States published far more articles (6819) concerning spinal fusion than any other country. It might be not surprising that the United States has retained overwhelming dominance in the field of spinal fusion, since it has been recognized as the most productive region in scientific and biomedical research for about several decades (18). The United States also had the highest total number of citations (164378) and the highest $\mathrm{H}$-index (144). However, the research productions of the population per million of the United States (21.22) were inferior to that of Switzerland (45.19), and the mean number of citations was lower than Sweden's (27.21). As for the research production and GDP, South Korea ranked the first (0.61 articles/billion), which might indicate a very strong contribution of GDP on publications. One interesting finding was that China published second highest number of articles $(n=1280, H$-index 33$)$, but the mean number of citations was the lowest (6.27) among the top 20 productive countries. The second lowest and third lowest countries for number of mean citations were Turkey (8.72) and India (10.75), both of which, combined with China, were middle-income or low-income countries. These middle-income or low-income countries may not have enough experience and resources to design a famous study (e.g. high-quality clinical trials) compared with developed countries. The developed countries have more advanced electronic data systems, so data collected for a study is more robust and credible. Another interesting finding was that neurosurgeons in most countries published more spinal fusion articles than orthopedic surgeons or at least the same amount, but orthopedic surgeons in China and Germany published far more articles $(>100)$ than neurosurgeons. This might be due to dominance of different medical subspecialties in different countries, as we observed in China, orthopedic surgeons performed most of the spine surgeries in clinical practice. In summary, the various geographic distributions of research activities were not surprising, because of differences in economic support, healthcare systems, funding sources and scientific research programs in different countries(8). However, the imbalanced ranking of research quantity and citations for some countries should be noted.

There were also unequal distributions of different journals in productive countries concerning spinal fusion. Among the top 5 productive countries, Spine was the most popular journal in 3 countries, including the United States, China, and Japan; European Spine Journal was the most popular in Germany, France and Switzerland, all of which were European countries. Journal of Korean Neurosurgical Society was the most popular in South Korea, and Chinese also preferred its own journals. Among the top 5 productive journals, the United States ranked the first in all included four journals, indicating absolute dominance in research productions. Among the top 5 productive countries/areas in journals with high impact factors, the United States also ranked the first in the four journals with high impact factors, which further indicated the largest number of academic contributions. However, China did not rank in the top 5 productive countries in journals with high impact factors, although it had the second largest volume of research productions. This finding was consistent with the abovementioned findings about China.

An approximate half a million spinal fusion procedures are performed in the United States each year, among which lumbar fusion is the most popular one, followed by cervical fusion and thoracic fusion. Our bibliometric analysis also found that most of the articles were about lumbar fusion, followed by cervical fusion and then thoracic fusion. Assessing the research productivity of academic subareas might provide a broader and more representative view of this field. Specifically, we 


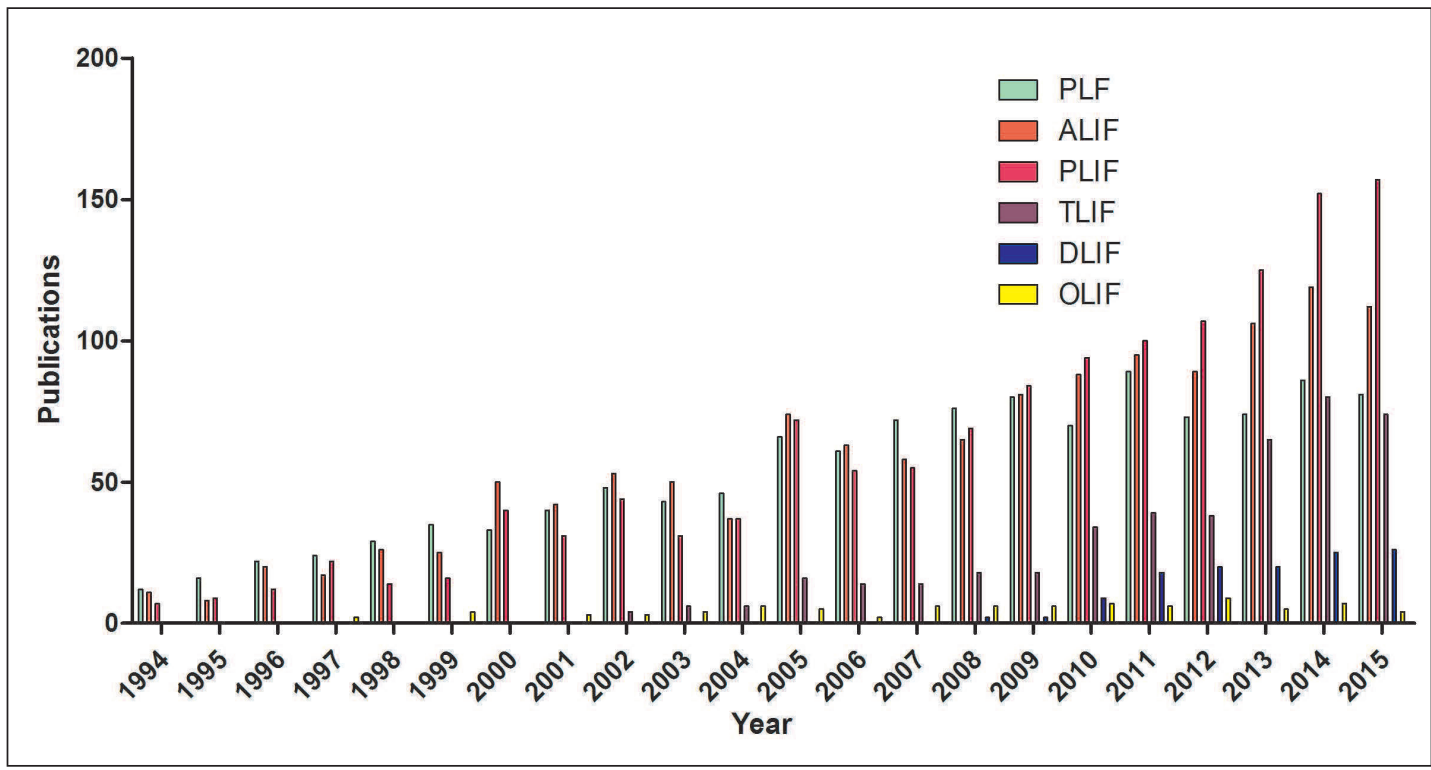

Figure 4: Time trends of research productivity concerning spinal fusion in popular lumbar fusion techniques.

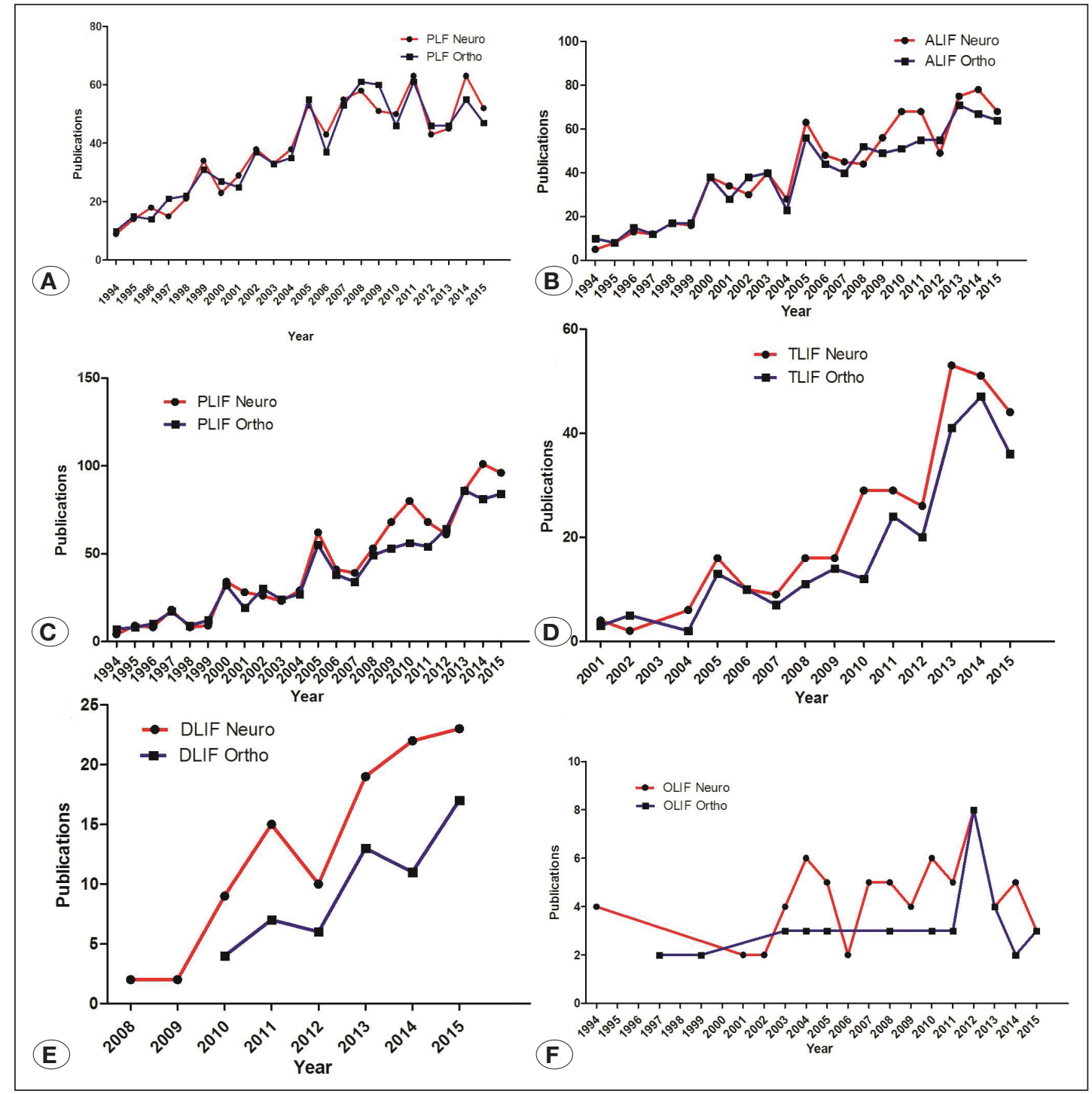

Figure 5: Time trends of research productivity concerning spinal fusion by different popular lumbar fusion techniques from different spine surgeons. A) PLF; B) ALIF; C) PLIF; D) TLIF; E) DLIF; F) OLIF. 
further depicted the research productivity of lumbar fusion in six common approaches over the past two decades, namely posterolateral lumbar fusion (PLF), anterior lumbar interbody fusion (ALIF), posterior lumbar interbody fusion (PLIF), transforaminal lumbar interbody fusion (TLIF), direct lateral interbody fusion (DLIF) and oblique lumbar interbody fusion (OLIF). It seems that PLF, ALIF, and PLIF have still been under investigation during the past few years, even though they were recently used to be compared with novel approaches such as DLIF and OLIF (Figure 4). We also investigated the research production difference of different surgeons in these six popular lumbar fusions. It seemed that neurosurgeons were more active than orthopedic surgeons in relatively novel approaches such as TLIF, DLIF and OLIF (Figure 5AF). Identifying significant shifts over time, not only suggested disequilibrium, but warranted further investigation and might influence the overall delivery of healthcare funding.

The current study has several limitations. First of all, it may make more sense to normalize the research production by the number of researchers and GDP invested in spinal fusion research in each country, not by the whole population and total GDP; however, it is rather difficult to obtain this data in the field of spine fusion research for each country. Instead, higher GDP has been well validated for being a positive factor for research productivity, which has been proved by previous studies $(8,9,18)$. It may be forecasted that the countries with rapid economic development could further improve their spinal fusion research in the future. Secondly, WoS database was used to search for spinal fusion studies, thus articles published in none WOS-cited journals were not included. However, this database is a well-accepted platform for bibliometric analysis. Last but not least, some researchers think that the frequently cited articles don't always mean they were of high citations, because of some arguable articles.

\section{- CONCLUSION}

The research productivity of spinal fusion has continued to increase over the past two decades. Neurosurgeons tend to publish more articles concerning spinal fusion, but orthopedic surgeons seem to have higher citations. North America, West Europe and East Asia were the most productive world regions in spinal fusion research, while the United States has made the most academic contributions to this area. This study may provide a research background for future investigation and a thought-provoking reference for policy-making.

\section{- REFERENCES}

1. Aluede EE, Phillips J, Bleyer J, Jergesen HE, Coughlin R: Representation of developing countries in orthopaedic journals: A survey of four influential orthopaedic journals. Clin Orthop Relat Res 470:2313-2318, 2012

2. Angevine PD, Arons RR, McCormick PC: National and regional rates and variation of cervical discectomy with and without anterior fusion, 1990-1999. Spine 28:931-939; discussion 940, 2003
3. Bae HW, Rajaee SS, Kanim LE: Nationwide trends in the surgical management of lumbar spinal stenosis. Spine 38:916926, 2013

4. Carragee EJ, Lincoln T, Parmar VS, Alamin T: A gold standard evaluation of the "discogenic pain" diagnosis as determined by provocative discography. Spine 31:2115-2123, 2006

5. Cowan JA Jr, Dimick JB, Wainess R, Upchurch GR Jr, Chandler WF, La Marca F: Changes in the utilization of spinal fusion in the United States. Neurosurgery 59:15-20; discussion 15-20, 2006

6. Deyo RA, Gray DT, Kreuter W, Mirza S, Martin BI: United States trends in lumbar fusion surgery for degenerative conditions. Spine 30:1441-1445; discussion 1446-1447, 2005

7. Deyo RA, Nachemson A, Mirza SK: Spinal-fusion surgery - the case for restraint. N Engl J Med 350:722-726, 2004

8. Ding F, Jia Z, Liu M: National representation in the spine literature: A bibliometric analysis of highly cited spine journals. Eur Spine J 25(3):850-855, 2016

9. Fan G, Han R, Zhang H, He S, Chen Z: Worldwide research productivity in the field of minimally invasive spine surgery: $A$ 20-year survey of publication activities. Spine (Phila Pa 1976) 42(22):1717-1722, 2017

10. Fan G, Zhou Z, Zhang H, Gu X, Gu G, Guan X, Fan Y, He S: Global scientific production of robotic surgery in medicine: $A$ 20-year survey of research activities. Int J Surg 30:126-131, 2016

11. Forsth P, Olafsson G, Carlsson T, Frost A, Borgstrom F, Fritzell $P$, Ohagen $P$, Michaelsson K, Sanden B: A randomized, controlled trial of fusion surgery for lumbar spinal stenosis. $\mathrm{N}$ Engl J Med 374:1413-1423, 2016

12. Ghogawala Z, Dziura J, Butler WE, Dai F, Terrin N, Magge SN, Coumans JV, Harrington JF, Amin-Hanjani S, Schwartz JS, Sonntag VK, Barker FG, 2nd, Benzel EC: Laminectomy plus fusion versus laminectomy alone for lumbar spondylolisthesis. N Engl J Med 374:1424-1434, 2016

13. Irwin ZN, Hilibrand A, Gustavel M, McLain R, Shaffer W, Myers M, Glaser J, Hart RA: Variation in surgical decision making for degenerative spinal disorders. Part I: Lumbar spine. Spine 30:2208-2213, 2005

14. Irwin ZN, Hilibrand A, Gustavel M, McLain R, Shaffer W, Myers M, Glaser J, Hart RA: Variation in surgical decision making for degenerative spinal disorders. Part II: Cervical spine. Spine 30:2214-2219, 2005

15. Jacobs WC, Rubinstein SM, Willems PC, Moojen WA, Pellise F, Oner CF, Peul WC, van Tulder MW: The evidence on surgical interventions for low back disorders, an overview of systematic reviews. Eur Spine J 22(9):1936-1949, 2013

16. Jacobs $\mathrm{WCH}$, Rubinstein SM, Willems PC, Moojen WA, Pellise F, Oner CF, Peul WC, van Tulder MW: The evidence on surgical interventions for low back disorders, an overview of systematic reviews. Eur Spine J 22:1936-1949, 2013

17. Katz JN: Lumbar spinal fusion. Surgical rates, costs, and complications. Spine 20:78s-83s, 1995

18. Li Q, Jiang $Y$, Zhang $M$ : National representation in the emergency medicine literature: A bibliometric analysis of highly cited journals. American Journal of Emergency Medicine 30:1530-1534, 2012 
19. Li Z, Qiu LX, Wu FX, Yang LQ, Sun YM, Lu ZJ, Yu WF: Assessing the national productivity in subspecialty critical care medicine journals: A bibliometric analysis. Journal of Critical Care 27:747.e741-745, 2012

20. McCutcheon BA, Ciacci JD, Marcus LP, Noorbakhsh A, Gonda DD, McCafferty R, Taylor W, Chen CC, Carter BS, Chang DC: Thirty-day perioperative outcomes in spinal fusion by specialty within the NSQIP database. Spine 40:1122-1131, 2015

21. Minhas SV, Chow I, Patel AA, Kim JY: Surgeon specialty differences in single-level anterior cervical discectomy and fusion. Spine 39:1648-1655, 2014
22. Peul WC, Moojen WA: Fusion for lumbar spinal stenosissafeguard or superfluous surgical implant? N Engl J Med 374:1478-1479, 2016

23. Rajaee SS, Bae HW, Kanim LE, Delamarter RB: Spinal fusion in the United States: Analysis of trends from 1998 to 2008. Spine 37:67-76, 2012

24. Wei MY, Wang WM, Zhuang YF: Worldwide research productivity in the field of spine surgery: A 10-year bibliometric analysis. Eur Spine J 25:976-982, 2016

25. Zhang WJ, Ding W, Jiang H, Zhang YF, Zhang JL: National representation in the plastic and reconstructive surgery literature: A bibliometric analysis of highly cited journals. Annals of Plastic Surgery 70:231-234, 2013 